\title{
Effects of infant feeding practices and maternal characteristics on early childhood obesity
}

\author{
Cuneyt Ardic, Assistant Professora ${ }^{a}$ Oguzer Usta, Research Assistant ${ }^{a}$, \\ Esma Omar, Research Assistant ${ }^{a}$, Cihangir Yildiz, Research Assistant ${ }^{a}$ and \\ Erdem Memis, Research Assistant ${ }^{a}$
}

\begin{abstract}
Introduction. Early childhood obesity is a serious health problem not only because it causes serious health problems in children, but also because it poses a risk of obesity in the later stages of life. Objective. The aim of our study was to determine theeffect of feeding (breastfeeding times, exclusive breastfeeding times, instances of night-time bottle feeding) and maternal characteristics (weight gain during pregnancy, BMI, socioeconomic status) on childhood overweight and obesity in children up to 36 months old.

Population and methods: Babies born in the province of Rize (Turkey) between the dates of November 1, 2013 and September 30, 2014 whom birth weights between $2500 \mathrm{gr}$ and $4500 \mathrm{gr}$ participated in our prospective cohort study. The present study lasted for 3 years and 11 interviews were conducted with each mother of the infants during this period. Relationship between obesity or overweight and feeding practices evaluated into two groups according to their feeding practices.
\end{abstract}

Results. 294 healthy children were included. Mean weight of the babies at 36 months were 14.6 kilograms, 6 babies ( $2 \%$ ) were overweight, 20 babies (7\%) were obese, and 268 babies (91\%) were at an normal weight. 82 babies (21\%) exclusive breastfed less than six months and 212 babies $(55 \%)$ exclusive breastfed six months or more. Overweight and obesity is less frequent among children who were exclusively breastfed for at least six months $(\mathrm{p}<0.05)$.

Conclusion. We concluded.that exclusive breastfeeding time and maternal obesity have a significant effect on childhood overweight and obesity.

a. Recep Tayyip Erdoğan University. Faculty of Medicine Department of Family Medicine. Rize, Turkey.

E-mail address: Cuneyt Ardic, Prof.: drcuneytardic@hotmail. com

Funding:

None.

Conflict of interest:

None.

Received: 3-18-2018

Accepted: 8-15-2018

\section{INTRODUCTION}

Childhood obesity has been increasing at an alarming rate for the last ten years. The World Health Organization (WHO) estimates that 42 million children under the age of 5 are currently obese. ${ }^{1}$

Childhood obesity is a health problem that requires attention because it continues as adult obesity in later stages of life, leads to serious increases in morbidity and mortality due to complications, and most importantly, it is mostly preventable..$^{2,3}$ The risk of developing type 2 diabetes mellitus (T2DM) and cardiovascular diseases including coronary heart disease, which is associated with an early death, is higher in obese children and teenagers. ${ }^{4,5}$

Early childhood is an important stage of life to prevent overweight in childhood, and there is increased need for research in this age group. Many variables including behavioral, genetic, and environmental factors can contribute to childhood obesity. Research shows that prenatal and early-life factors such as the mother's body mass index (BMI), whether the mother smokes, gestational weight gain, and gestational diabetes have an effect on early childhood obesity. ${ }^{6}$

It is well known that breastfeeding leads to a decrease in the morbidity and mortality rates in babies providing optimal growth and development as well as financial benefits to the parents and the country. ${ }^{7}$ The World Health Organization and UNICEF recommend that babies are exclusively breastfed in their first 6 months, they should be given supplementary food starting at their $7^{\text {th }}$ month. ${ }^{8}$ Several studies indicate that breastfeeding has a protective effect against morbid 
weight gain in childhood., ${ }^{9,10}$ Several mechanisms exist by which breastfeeding may influence childhood overweight and obesity, including the influence of the hormonal makeup of breast milk compared to formula and the influence of breastfeeding on rapid weight gain in infancy. ${ }^{11}$

The World Health Organization (WHO) and the American Pediatric Association (APA) determined the time for introducing supplementary food to babies as 6 months. ${ }^{12}$ Studies show that the timing of the introduction of supplementary food leads to childhood obesity. In obesity. ${ }^{13-15}$ In some studies, the reason for this is speculated to be the fact that when children are breastfed, they have the opportunity to determine how much to consume themselves whereas when they are fed with formula milk or supplementary food, babies cannot sense their own satiation. ${ }^{16}$

Another problem that might cause obesity in early childhood is the fact that children are fed with a bottle at nights. The few studies that examined this issue concluded that children who go to bed with a bottle in their hands experience early childhood overweight or obesity. ${ }^{11,17}$

These causes, as well as other healthy feeding practices for babies, are potential reasons for intervention to help decrease the risk of developing early childhood obesity among children. As far as we know, our study was the first to examine overweight and obesity in early childhood in Turkey, and our aim was to determine the effect of feeding (breastfeeding times, exclusive breastfeeding times, instances of night-time bottle feeding) and maternal characteristics (weight gain during pregnancy, BMI, socioeconomic status) on childhood overweight and obesity in children up to 36 months old.

\section{MATERIALS AND METHODS Data Source}

Babies born in the province of Rize between November 1, 2013 and September 30, 2014 and their mothers participated in our prospective cohort study. Patinents who included the study consist of people that have records at "Rize Family Health Center" and their follow-ups done at this center.

Mothers were examined by the same family doctors during their pregnancies, and likewise, babies were also regularly examined by the same family doctors until they all were 36 months old. The study continued until all babies reached 36 months of age. The family doctors participating in this study examined these babies who were registered with them during their $1^{\text {st }}, 3^{\text {rd }}, 7^{\text {th }}$, $9^{\text {th }}, 12^{\text {th }}, 18^{\text {th }}, 24^{\text {th }}, 30^{\text {th }}, 36^{\text {th }}$ months at the family health centers in accordance with Turkish Health Ministry protocols and recorded their height, weight, head circumference, and BMI (Body Mass Index).

\section{Inclusion criteria}

Babies whom birth weights between 2500gr and $4500 \mathrm{gr}$ included in study. The babies who were born with a weight less than 2500 grams and more than 4500 grams because children with extremely low birth weight may follow very different height and weight growth trajectories than babies born with a normal birth weight. ${ }^{18}$

\section{Exclusion criteria}

- Babies with congenital heart disease, congenital immune system deficiency, malabsorption syndrome, and those diagnosed with phenylketonuria were also excluded because these conditions might have an effect on the weight and height percentiles of the babies.

- Elimination criterion is the lack of regular control until 36 months of age.

\section{Ethical procedure}

Ethics committee approval for this study was taken from the Ethics Committee of Recep Tayyip Erdoğan University Faculty of Medicine. In addition, informed consent forms were obtained from the mothers in their pregnancy.

\section{Measuring Weight Status}

Scales sensitive to $0.01 \mathrm{~kg}$ were used to measure the babies' weights. Babies' clothes and diapers, if any, were removed before the measurements were made, and their weights were recorded when they were not moving. Children who were over 2 years old removed their shoes when their height was being measured and they were weighted with underwear or light clothing and without shoes.

The CDC's 2000 reference growth charts were used to classify children's weight status into one of three commonly used categories. ${ }^{19,20}$ Children with percentiles less than 85 were classified as having a healthy weight status. Children whose body mass percentiles fell between 85 and 94 were considered overweight, whereas, children with percentiles at or above 95 were categorized as obese. 


\section{Maternal characteristics}

Family doctors collected pregnancymonitoring forms of all mothers participating in the study at least four times in total, at least once in each trimester. Mothers' pre-pregnancy weights were recorded, their weight and height during their last trimesters were measured, and their total weight gain during pregnancy was calculated. Moreover, the weight and height of all the mothers were measured again when the children became three years old, and their BMI was calculated.

The mothers who did not regularly attend follow-up visits for any reason in their pregnancy, those with a multiple pregnancy and those diagnosed with a chronic disease were excluded from the study.

Educational level of the mother determined at first follow-up after the birth. They are seperated into two groups according to their educational level as primary school graduted and high school graduted or higher degrees. Monthly income level of the families calculated as total monthly earnings of the people in home who are working. This situation asked to families at birth, when baby is 12 months old, 24 months old and 36 months old and average of these values calculated. According to this families seperated into three groups as monthly income level less than 1000 dollars, between 1000-2000 dollars and more than 2000 dollars.

\section{Breastfeeding and Solid Food Introduction}

During each interview we made with the mothers participating in the study (during the $1^{\text {st }}, 3^{\text {rd }}, 7^{\text {th }}, 9^{\text {th }}, 12^{\text {th }}, 18^{\text {th }}, 24^{\text {th }}$ and $34^{\text {th }}$ months of the babies), we asked them whether they were breastfeeding, whether they were feeding supplementary food to the babies (formula milk or solid food), and if they were feeding solid food and when they started to do so and recorded their answers. Given the American Academy of Pediatrics recommendation that infants be breastfed exclusively for 6 months ${ }^{12}$, we focused our analysis on predominant breastfeeding to 6 months. In the analysis, predominant breastfeeding was the reference category.

Another question regarding the feeding of babies was whether children were fed cow milk or formula milk before they went to bed. We asked until what month of age children went to bed with a bottle considering the answers provided by the mothers. We separated the children into two groups as those who were bottle fed for less than
24 months and those who were bottle fed for or more than 24 months.

\section{Statistical analysis}

Statistical analysis was carried out using the software R. We used descriptive analysis to examine the demographic characteristics of children 2 and 3 years of age. Chi-square tests were used to examine the relationship the children's being obese and other characteristics.

The relationship between consuming milk and supplementary food at night and being extremely overweight or obese at the age of 3 was examined using relative possibility rate (PR) based on log-binomial regression. Potential covariates in the model were total breast milk consumption, milk consumption at night, and consuming supplementary food. Covariates were included in the final model comparing the relationship between consuming milk and supplementary food at night and being extremely overweight or obese at the age of 3 . covariates included the mother's age, BMI value, weight gain during pregnancy, socioeconomic status, baby's gender, and weight at birth. We accepted $p<0.05$ value as statistically significant.

\section{RESULTS}

Our study started with 364 babies, but after the application of the exclusion criteria, we completed the study with 294 children (Figure 1).

Two hundred and ninety four babies included in study and 164 of them were boys and 130 were girls. Mean birth weight of the babies was $3640 \mathrm{gr}$ at birth and $14600 \mathrm{gr}$ at 36 months. $6(2 \%)$ of the babies were overweight, $20(7 \%)$ of them were obese and $269(91 \%)$ of them were at an acceptable weight. Average age of the mothers who participated in study was 28.7 and average BMI of them was $26.7 \mathrm{~kg} / \mathrm{m} 2$. Moreover, 132 mothers $(45 \%)$ were at an acceptable weight, 107 mothers (36\%) were overweight, and 55 mothers $(19 \%)$ were obese. The other socio-demographic characteristics of the mothers and babies participating in the study are shown in Table 1.

Table 2 shows the relationship between how the children were fed (exclusively breastfed, time of introduction of solid food, duration of bottle-feeding), the mothers' BMI, and the weight of the babies at 36 months of age. Overweight and obesity is less frequent among children who were exclusively breastfed for at least six months $(p<0.05)$. Moreover, there is a relationship between the mother's being obese 
and the child's being overweight or obese at 36 months of age $(p<0.05)$. We did not find any relationship between the duration of total breast milk consumption at night and the children's being overweight or obese at 36 months of age and between the total duration of breast milk consumption and childhood obesity ( $p>0.05)$.

Table 3 shows the results from the log-binomial regression analysis. Overweight and obesity were less frequent among children who were exclusively breastfed at least for 6 months than those who were exclusively breastfed for less than 6 months when the children reached 36 months of age with adjustment for the mother's age, weight gain during pregnancy, level of education, baby's gender, and monthly income (adjusted odds ratio $3.32,95 \%$ CI 0.41-3.64).

\section{DISCUSSION}

The results of our study support the relationship between how children are fed during the first few years of their lives (duration of consuming breast milk, the time of introduction to supplementary food) and development of overweight and obesity until the age of 3 . Whether reported as differences in prevalence rates or as odds ratios, there is a positive relationship between delaying the introduction

FIGURE 1: Flow diagram for selection of participants

Babies born in the province of Rize between November 1, 2013 and September 30, 2014 $n=426$

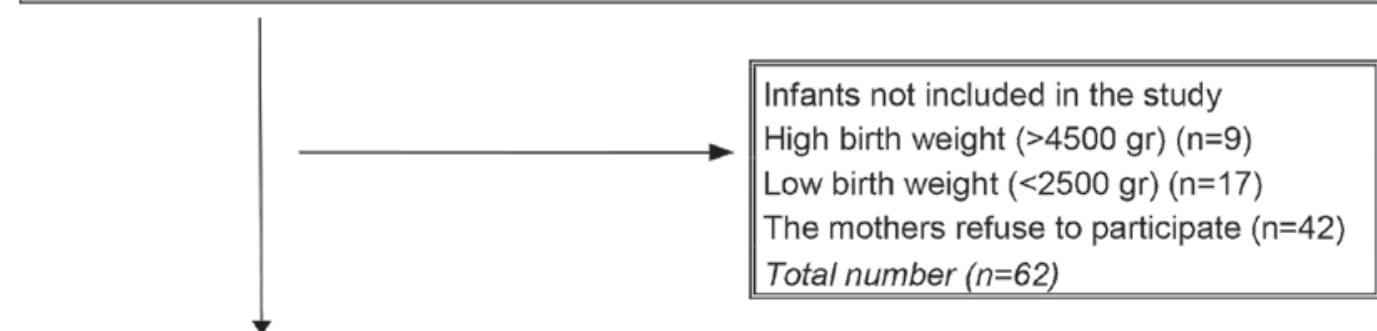

Eligible Infants in the study $n=364$

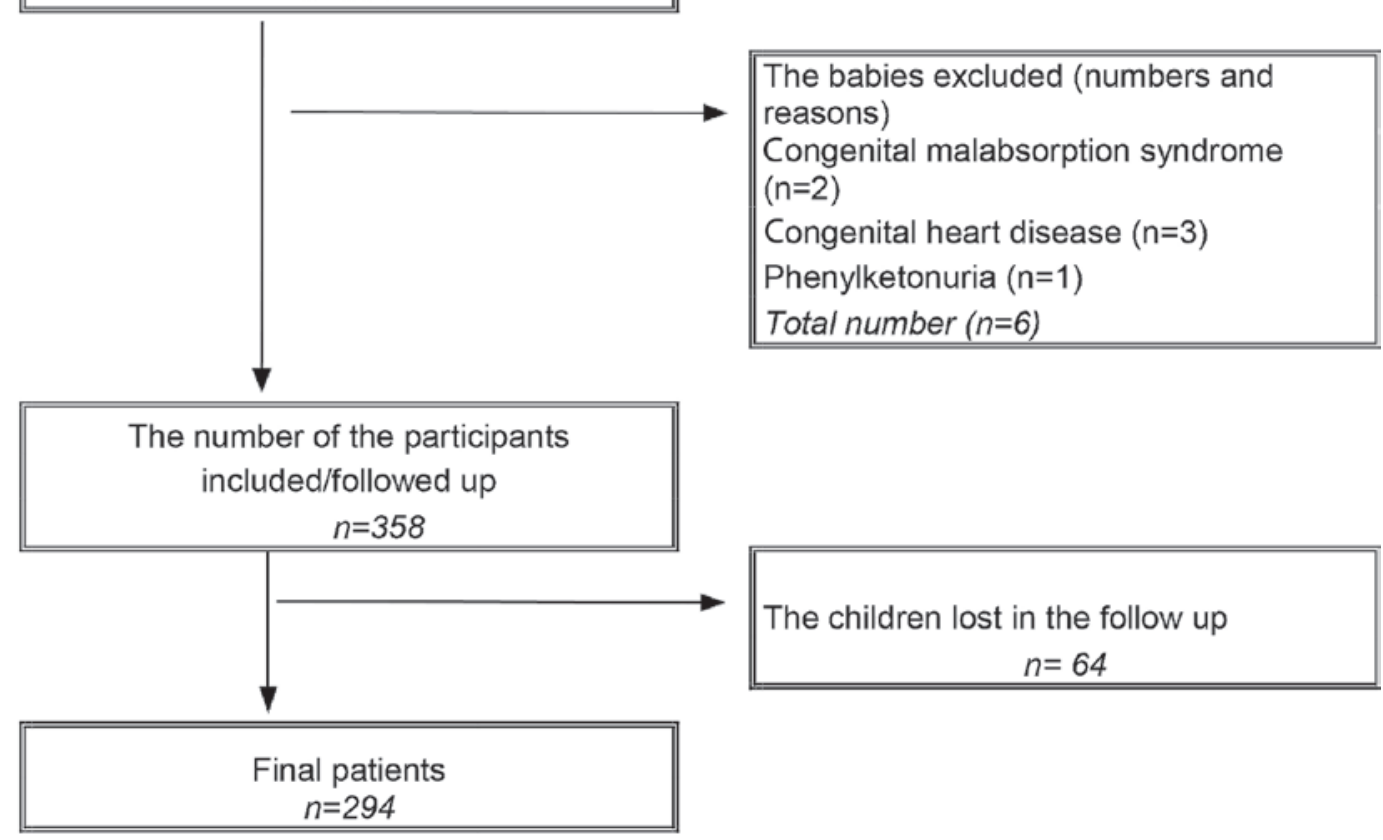


of supplementary food and decreasing the time of milk consumption at night, and the development of overweight and obesity in early childhood. This analysis might be a guide for obesity prevention programs for children.

Although there are studies in the literature on the importance of breast milk in preventing childhood obesity ${ }^{21-23}$, the effective mechanism is still unclear. One possible explanation for breast milk's positive impact might be that consuming

TABLE 1: Perinatal characteristics, breastfeeding history and weight status of children aged 36 months

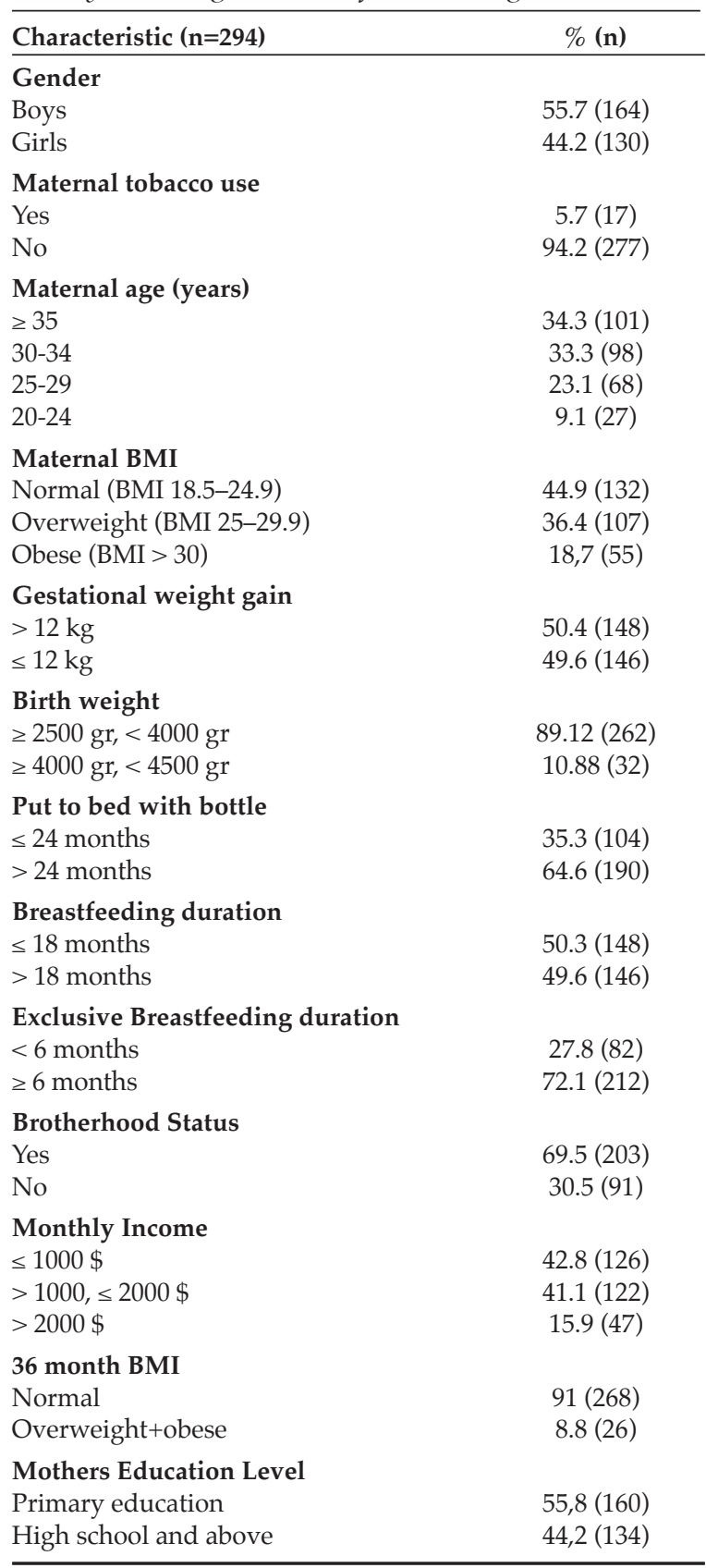

breast milk might help to improve children's ability to control their food consumption and sense their satiation. ${ }^{16}$ On the contrary, children who were introduced to bottle-feeding in their early childhood might fail to improve their control over their satiation, and thus, have a tendency to gain weight. ${ }^{24}$ On the other hand, children who start supplementary food before they reach 6 months of age are given food items with high caloric content, and they might, therefore, have a tendency to gain weight in early childhood. ${ }^{11}$ The eating habits that begin in early childhood might become permanent and pose a risk to their health later.

In a study conducted by Brophy et al. ${ }^{25}$ in 2009 , it was observed that children who were given solid food before they reached 3 months of age tend to become more obese at the age of 5. Likewise, in a study conducted by Huh et al. ${ }^{13}$ in 2011, it was discovered that the introduction of supplementary food before children reached 4 months of age led to the development of obesity at the age of 3 . Our study also showed that children who started supplementary food before they reached 6 months of age had a tendency to become obese or overweight in their BMI measurements at the age of 3 .

A study conducted by Gillman M.W. Et al. ${ }^{26}$ showed a negative relationship between the total time of breastfeeding and childhood obesity. Furthermore, a study conducted by De Jesus et al. ${ }^{22}$ discovered that the risk of obesity during the first year of infancy decreased among children who were exclusively breastfed during their first 4 months. We also found out that the duration of exclusive breastfeeding has a negative relationship with the risk of developing obesity. This might be due to the fact that once the supplementary food is introduced, the total amount of consumed breast milk decreases, and the total caloric intake increases.

Another important result of our study is that there is a relationship between the mother's obesity and early childhood obesity or overweight. This result is consistent with previous studies. For example, in the study conducted by Whitaker et al., it was determined that childhood obesity at the age of 2 was more frequent among children whose mothers were obese than children whose mothers were not obese. ${ }^{27}$ Our study also showed that children whose mothers were obese tend to be more obese at the age of 3 compared to those children whose mothers were not obese $(p<0.05)$. This can be explained with the effect of 
genetics on obesity and the effect of the parents' eating habits on the child's eating habits.

In addition, research has demonstrated that bottle-feeding and putting a child to bed with a bottle are associated with overweight or obesity in childhood. ${ }^{28}$ Brown A. et al. conducted a study where they found out that bottle-feeding causes babies to change their eating habits and increased

TABLE 2: Perinatal characteristics and breastfeeding history by current weight status of children at 36 months

\begin{tabular}{|c|c|c|c|c|}
\hline & $(\mathrm{n}=294)$ & $\begin{array}{l}\text { Normal } \\
\%(\mathrm{n})\end{array}$ & $\begin{array}{c}\text { Overweight+obese } \\
\%(\mathrm{n})\end{array}$ & $P^{*}$ value \\
\hline $\begin{array}{l}\text { Gender } \\
\text { Boys } \\
\text { Girls }\end{array}$ & $\begin{array}{l}164 \\
130\end{array}$ & $\begin{array}{l}89.6(147) \\
93.1(121)\end{array}$ & $\begin{array}{c}10.4(17) \\
6.9(9)\end{array}$ & .30 \\
\hline $\begin{array}{l}\text { Birth weight } \\
\geq 2500 \mathrm{gr}_{r}<4000 \mathrm{gr} \\
\geq 4000 \mathrm{gr}, \leq 4500 \mathrm{gr}\end{array}$ & $\begin{array}{c}262 \\
32\end{array}$ & $\begin{array}{l}93.5(245) \\
71.9(23)\end{array}$ & $\begin{array}{l}6.5(17) \\
28.1(9)\end{array}$ & $<.001$ \\
\hline $\begin{array}{l}\text { Breastfeeding duration } \\
\leq 18 \text { months } \\
>18 \text { months }\end{array}$ & $\begin{array}{l}148 \\
146\end{array}$ & $\begin{array}{l}91.3(135) \\
91.1(133)\end{array}$ & $\begin{array}{l}8.7(13) \\
8.9(13)\end{array}$ & .95 \\
\hline $\begin{array}{l}\text { Exclusive Breastfeeding duration } \\
<6 \text { months } \\
\geq 6 \text { months }\end{array}$ & $\begin{array}{c}82 \\
212\end{array}$ & $\begin{array}{c}85.4(70) \\
93.4(198)\end{array}$ & $\begin{array}{c}14.6(12) \\
6.6(14)\end{array}$ & .02 \\
\hline $\begin{array}{l}\text { Put to bed with bottle duration } \\
<24 \text { months } \\
\geq 24 \text { months }\end{array}$ & $\begin{array}{l}130 \\
164\end{array}$ & $\begin{array}{l}92.3(120) \\
90.2(148)\end{array}$ & $\begin{array}{l}7.7(10) \\
9.8(16)\end{array}$ & .53 \\
\hline $\begin{array}{l}\text { Maternal BMI } \\
\text { Normal } \\
\text { Overweight+obese }\end{array}$ & $\begin{array}{l}132 \\
162\end{array}$ & $\begin{array}{l}94.7(125) \\
88.3(143)\end{array}$ & $\begin{array}{c}5.3(7) \\
11.7(19)\end{array}$ & .048 \\
\hline $\begin{array}{l}\text { Gestational weight gain } \\
\leq 12 \mathrm{~kg} \\
>12 \mathrm{~kg}\end{array}$ & $\begin{array}{l}146 \\
148\end{array}$ & $\begin{array}{l}91.8(135) \\
90.5(133)\end{array}$ & $\begin{array}{l}8.2(12) \\
9.5(14)\end{array}$ & .68 \\
\hline $\begin{array}{l}\text { Monthly Income } \\
\leq 1000 \$ \\
>1000, \leq 2000 \$ \\
>2000 \$\end{array}$ & $\begin{array}{c}126 \\
121 \\
47\end{array}$ & $\begin{array}{l}91.3(115) \\
91.7(111) \\
89.4(42)\end{array}$ & $\begin{array}{l}8.7(11) \\
8.3(10) \\
10.6(5)\end{array}$ & .85 \\
\hline $\begin{array}{l}\text { Mother Education } \\
\text { Primary education } \\
\text { High school and above }\end{array}$ & $\begin{array}{l}164 \\
130\end{array}$ & $\begin{array}{l}92.0(151) \\
90.0(117)\end{array}$ & $\begin{array}{c}8.0(13) \\
10.0(13)\end{array}$ & .54 \\
\hline
\end{tabular}

${ }^{*} \mathrm{P}<0.05$. The statistical significance was determined by the Chi-square test.

TABLE 3: Crude and adjusted prevalence ratios of childhood overweight or obesity at 36 months for selected characteristics

\begin{tabular}{|c|c|c|c|c|}
\hline & OR & $95 \% \mathrm{CI}$ & AOR & $95 \% \mathrm{CI}$ \\
\hline $\begin{array}{l}\text { Breastfeeding duration } \\
\leq 18 \text { months } \\
>18 \text { months }\end{array}$ & $\begin{array}{c}1[\operatorname{Ref}] \\
1,01\end{array}$ & [0.44-2.23] & $\begin{array}{c}1 \text { [Ref] } \\
1,02\end{array}$ & [0.44 - 2.40] \\
\hline $\begin{array}{l}\text { Put to bed with bottle duration } \\
<24 \text { months } \\
\geq 24 \text { months }\end{array}$ & $\begin{array}{c}1 \text { [Ref] } \\
1,29\end{array}$ & $\begin{array}{c}1 \text { [Ref] } \\
{[0.56-2.96]}\end{array}$ & 1,27 & {$[0.53-3.12]$} \\
\hline $\begin{array}{l}\text { Exclusive breasfeeding duration } \\
<6 \text { months } \\
\geq 6 \text { months }\end{array}$ & $\begin{array}{c}2.42^{*} \\
1 \text { [Ref] }\end{array}$ & [1.07-5.49 ] & $\begin{array}{c}3.32^{*} \\
1[\text { Ref] }\end{array}$ & {$[0.41-3.64]$} \\
\hline $\begin{array}{l}\text { Maternal BMI } \\
\text { Normal } \\
\text { Overweight+obese }\end{array}$ & $\begin{array}{c}1[\text { Ref] } \\
2.37^{*}\end{array}$ & [0.96- 5.83] & $\begin{array}{c}1 \text { [Ref] } \\
1.35\end{array}$ & [0.88-3.98] \\
\hline
\end{tabular}

Odds ratios adjusted for maternal education, maternal age, monthly income, children's birth weight and gender, Gestational weight gain

${ }^{*}: \mathrm{p}<0.05$.

CI: confidence interval; OR: odds ratio; AOR: adjusted odds ratio; BMI: Body Mass Index.

Ref: reference value. 
calorie intake. In our study, we also found that children who went to bed with a bottle tend to be more obese at the age of 3; however, this result was not statistically significant.

One strength of the study was that we observed children at least 7 times before they reached the age of 3 , and all the observations were conducted by the same family doctors. Another factor adding to the strength of our study is that all mothers participating in our study were observed by the same family doctors at least 4 times during their pregnancies. One of the facts that prevent any misinterpretation is that questions regarding the babies' eating habits were asked to the mothers at each meeting face-to-face.

That we did not ask about the nutritional composition of the food given to the babies in bottles and did not determine the nutritional values can be considered a limitation.

\section{CONCLUSIONS}

We concluded that variables related to the eating habits of babies are especially important in early childhood, and exclusive breastfeeding time, the time of introduction of solid food, and mothers' BMI values have an effect on early childhood overweight and obesity. Necessary steps should be taken in this regard since it is predicted that early childhood obesity will probably continue in the later stages of life in children.

\section{REFERENCES}

1. World Health Organization. Obesity and overweight. [Accessed on: august 16, 2018]. Available at: http:/ / www.who. int/mediacentre/factsheets/fs311/en/

2. Biro FM, Wien M. Childhood obesity and adult morbidities. Am J Clin Nutr. 2010;91(5):1499S-1505S.

3. Singh AS, Mulder C, Twisk JWR, Van Mechelen W, et al. Tracking of childhood overweight into adulthood: A systematic review of the literature. Obes Rev. 2008;9(5):474-88.

4. Park MH, Falconer C, Viner RM, Kinra S. The impact of childhood obesity on morbidity and mortality in adulthood: A systematic review. Obes Rev. 2012;13(11):985-1000.

5. Juonala M, Magnussen CG, Berenson GS, Venn A, et al. Childhood Adiposity, Adult Adiposity, and Cardiovascular Risk Factors. Obstet Gynecol Surv. 2012;67(3):156-8.

6. Oken E, Kleinman KP, Belfort MB, Hammitt JK, et al. Associations of Gestational Weight Gain With Short- and Longer-term Maternal and Child Health Outcomes. Am J Epidemiol. 2009;170(2):173-80.

7. Lauwers J, Swisher A. Counseling the Nursing Mother: a Lactation Consultant's Guide. 5th ed. Sudbury: Jones \& Bartlett Learning; 2011.

8. World Health Organization. Nurition. The World Health Organization's infant feeding recommendation. WHO. [Accessed on: august 16, 2018]. Available at: http:/ / www. who.int/nutrition/topics / infantfeeding_recommendation/en/.

9. Wijlaars LP, Johnson L, van Jaarsveld CH, Wardle J. Socioeconomic status and weight gain in early infancy. Int $\mathrm{J}$ Obes (Lond). 2011;35(7):963-70.

10. McCrory C, Layte R. Breastfeeding and risk of overweight and obesity at nine-years of age. Soc SciMed.2012;75(2):32330.

11. Taveras EM, Scanlon KS, Birch L, Rifas-Shiman SL, et al. Association of Breastfeeding With Maternal Control of Infant Feeding at Age 1. Pediatrics. 2004;114(5):e577-83.

12. Eidelman AI, Schanler RJ. Breastfeeding and the use of human milk. Pediatrics. 2012;129(3):e827-41.

13. Huh SY, Rifas-Shiman SL, Taveras EM, Oken E, et al. Timing of Solid Food Introduction and Risk of Obesity in Preschool-Aged Children. Pediatrics. 2011;127(3):e544-51.

14. Moss BG, Yeaton WH. U.S. children's preschool weight status trajectories: Patterns from 9-month, 2-year, and 4-year Early Childhood Longitudinal Study-Birth cohort data. Am J Heal Promot. 2012;26(3):172-5.

15. Barrera CM, Perrine CG, Li R, Scanlon KS. Age at Introduction to Solid Foods and Child Obesity at 6 Years. Child Obes. 2016;12(3):188-92.

16. Li R, Fein SB, Grummer-Strawn LM. Do Infants Fed From Bottles Lack Self-regulation of Milk Intake Compared With Directly Breastfed Infants? Pediatrics. 2010;125(6):e1386-93.

17. Brown A, Lee M. Breastfeeding during the first year promotes satiety responsiveness in children aged 18-24 months. Pediatr Obes. 2012;7(5):382-90.

18. Hack M, Schluchter M, Cartar L, Rahman M, et al. Growth of Very Low Birth Weight Infants to Age 20 Years. Pediatrics. 2003;112(1 Pt 1):e30-8.

19. Kuczmarski RJ, Ogden CL, Grummer-Strawn LM, Flegal KM, et al. CDC Growth Charts: United States. Adv Data. 2000;(314):1-27.

20. Ogden CL, Flegal KM. Changes in terminology for childhood overweight and obesity. Natl Health Stat Report. 2010;(25):1-5.

21. Kramer MS, Matush L, Vanilovich I, Platt RW, et al. Effects of prolonged and exclusive breastfeeding on child height, weight, adiposity, and blood pressure at age $6.5 \mathrm{y}$ : Evidence from a large randomized trial. Am J Clin Nutr. 2007;86(6):1717-21.

22. Jesus GM, Vieira GO, Vieira TO, Martins Cda C, et al. Determinants of overweight in children under 4 years of age. J Pediatr (Rio J). 2010;86(4):311-6.

23. Wang L, Collins C, Ratliff M, Xie B, et al. Breastfeeding Reduces Childhood Obesity Risks. Child Obes. 2017;13(3):197204.

24. Fisher JO, Birch LL, Smiciklas-Wright H, Picciano MF. Breast-feeding through the first year predicts maternal control in feeding and subsequent toddler energy intakes. J Am Diet Assoc. 2000;100(6):641-6.

25. Brophy S, Cooksey R, Gravenor MB, Mistry R, et al. Risk factors for childhood obesity at age 5: Analysis of the Millennium Cohort Study. BMC Public Health. 2009;9:467.

26. Gillman MW, Rifas-Shiman SL, Camargo CA Jr, Berkey CS, et al. Risk of overweight among adolescents who were breastfed as infants. JAMA. 2001;285(19):2461-7.

27. Whitaker RC. Predicting Preschooler Obesity at Birth: The Role of Maternal Obesity in Early Pregnancy. Pediatrics. 2004;114(1):e29-36.

28. Kimbro RT, Brooks-Gunn J, McLanahan S. Racial and ethnic differentials in overweight and obesity among 3-yearold children. Am J Public Health. 2007;97(2):298-305. 